\title{
Avaliação de um Protocolo de Assistência Pré-natal de Baixo Risco no HC-UNICAMP
}

Autor: Carlos Eduardo Ferreira

Orientador: Prof. Dr. Belmiro Gonçalves Pereira

Co-Orientadora: Prof. Dra. Mary Ângela Parpinelli

Dissertação de Mestrado apresentada à Pós-Graduação da Faculdade de Ciências Médicas da Universidade Estadual de Campinas em 25 de fevereiro de 2002.

O objetivo deste estudo foi avaliar um novo protocolo de assistência pré-natal de baixo risco implantado no Hospital das Clínicas da UNICAMP em julho de 1996 em relação ao diagnóstico de estados patológicos (anemia, infecção urinária, sífilis, HIV, hepatite B, toxoplasmose, rubéola, vulvovaginite e diabetes gestacional). Foi realizado um estudo de coorte, retrospectivo, operacional, tipo ensaio clínico com abordagem antes e depois da introdução do novo protocolo. Foram estudadas 250 grávidas deste protocolo e 250 do protocolo anterior. Os critérios de inclusão foram: gestantes que ingressaram no pré-natal até no máximo com 28 semanas de gestação e compareceram a pelo menos quatro consultas. As análises dos dados, para algumas variáveis, foram realizadas pelo teste exato de Fisher e regressão logística. Para outras variáveis, as análises foram apenas descritivas. O nivel de significância preestabelecido foi de 5\%. Concluímos que o novo protocolo foi aplicado a pacientes mais jovens. Este protocolo levou ao diagnóstico de 10,8\% e 29\% de anemia, respectivamente no primeiro e terceiro trimestres de gestação; permitiu maior número de diagnóstico de infecção urinária e menor de sífilis em relação ao antigo protocolo. O novo protocolo identificou $45 \%$ e $25 \%$ de gestantes suscetiveis à toxoplasmose e rubéola, respectivamente. Em relação ao diabetes gestacional, com a aplicação do novo protocolo diagnosticou-se $17,4 \%$ de glicemia de jejum alterada. Vinte e seis por cento das gestantes do novo protocolo apresentaram vulvovaginite confirmada por bacterioscopia de secreção vaginal no primeiro trimestre e $18 \%$ no terceiro trimestre.

Palavras-chave: Diagnóstico pré-natal. Assistência primária à Saúde. Pré-natal. Diagnóstico laboratorial. Anemia. Infecções na gravidez.

\section{Efeitos do 17/ estradiol Sublingual sobre a Vasodilatação Endotélio Dependente e Independente em Mulheres Normo e Hipertensas após a Menopausa}

Autor: Sônia Maria Rolim Rosa Lima

Orientador: Prof. Dr. José Mendes Aldrighi

Tese apresentada à Faculdade de Medicina da Universidade de São Paulo para a obtenção do título de Doutor em Medicina, em 8 de abril de 2002.

Objetivos: Estudar os benefícios do $17 \beta$ estradiol sublingual no endotélio de mulheres normotensas e hipertensas após a menopausa, visando a melhora do fluxo sangüíneo arterial (vasodilatação endotélio dependente e independente), a resistência vascular e a alteração da pressão arterial.

Métodos: Foram estudadas 15 mulheres: Grupo I (n=8) normotensas (55,8 5 anos) do Ambulatório de Saúde da Mulher no Climatério da Faculdade de Saúde Pública da USP e Grupo II $(n=7)$ com hipertensão leve e moderada (54,4 5 anos), sem outros fatores de risco para doença cardiovascular, do Ambulatório de Hipertensão do InCor da Faculdade de Medicina da USP. O fluxo sangüineo arterial (FSA) foi estudado através da técnica da pletismografia por oclusão venosa (strain-gauge plethysmography), após punção da artéria braquial do membro superior não dominante no período basal e durante a infusão intra-arterial de acetilcolina (ACh) $(0,75,5$ e 15 $\mathrm{mg} / \mathrm{min} / 100 \mathrm{~mL}$ de tecido) e nitroprussiato de sódio (NP) (1, 2 e $4 \mathrm{mg} / \mathrm{min} / 100 \mathrm{~mL}$ de tecido), com intervalos de 20 minutos, antes e após 40 minutos da administração sublingual do $17 \beta$ estradiol. A pressão arterial e a fre- qüência cardíaca foram registradas pelo Finapress. Resultados: A análise das curvas dose resposta demonstrou que a pressão arterial média (PAM) não se alterou durante todo o estudo. O FSA foi semelhante em ambos os grupos no período basal, porém após a administração do $17 \beta$ estradiol, a ACh causou um aumento significativo no FSA proporcional a dose, em ambos os grupos, o mesmo ocorrendo com o NP. Em relação a resistência arterial, a administração do $17 \beta$ estradiol provocou queda em ambos os grupos. Concluiu-se que o $17 \beta$ estradiol por via sublingual potencializou a vasodilatação endotélio-dependente e independente em mulheres normotensas e hipertensas após a menopausa, com melhora significativa do fluxo sangüineo arterial, provocou queda significativa da resistência vascular, não alterou os níveis da pressão arterial e a presença de hipertensão arterial leve e moderada não propiciou piora adicional sobre a disfunção endotelial preexistente.

Palavras-chave: Menopausa. Hipertensão arterial. Resistência vascular. Pletismografia. Endotélio. 


\section{Neoplasia Intra-epitelial Cervical em Mulheres Soro-positivas para o Virus da Imunodeficiência} Humana

Autor: Orlando Monteiro Júnior

Orientador:Prof. Dr. Paulo Traiman

Dissertação apresentada à Faculdade de Medicina de Botucatu - UNESP (Programa de Pós-Graduação em Ginecologia e Obstetrícia, área de concentração em Ginecologia, nível de Mestrado em 7 de maio de 2001

Objetivando estudar a prevalência de neoplasia intraepitelial cervical (NIC) em mulheres soro-positivas para o vírus da imunodeficiência humana (HIV) ao comparálas com um grupo controle de mulheres soro-negativas, foi realizado um trabalho retrospectivo em que foram avaliadas 86 mulheres HIV positivas e $86 \mathrm{mu}-$ lheres HIV negativas, que freqüentaram um Serviço Público de acompanhamento em DST/AIDS na cidade de Campo Grande, Mato Grosso do Sul, Brasil. Foram realizadas avaliações citológicas pelo Papanicolaou, colposcopias e biópsias quando indicadas. Encontrouse uma prevalência maior de NIC no grupo de mulhe- res HIV positivas em comparação ao grupo de mulheres HIV negativas, e esta diferença foi estatisticamente significativa. Conclui o autor que, sendo o câncer do colo uterino uma patologia previnível e com o atual aumento da expectativa de vida das pacientes HIV positivas, este grupo de mulheres merece atenção ginecológica diferenciado com consultas mais freqüentes e livre acesso à colposcopia.

Palavras-chave: Colo: Lesões pré-neoplásicas. Neoplasia intra-epitelial cervical (NIC). Vírus da imunodeficiência humana (HIV). Colpocitologia.

\section{Terapia Antibiótica na Prevenção do Parto Pré-Termo: Estudo Prospectivo Aleatório e Duplo-Cegóo}

Autora: Marília da Glória Martins

Orientadora: Prof $^{\mathrm{a}} \mathrm{Dr}^{\mathrm{a}}$. Anna Maria Bertini

Co-orientador: Prof. Dr. Wladimir Taborda

Tese apresentada à Universidade Federal de São Paulo - Escola Paulista de Medicina para obtenção do título de Doutor, em 10 de dezembro de 2001.

Objetivo: Avaliar a eficácia da amoxicilina associada ao metronidazol no prolongamento da gravidez em pacientes complicadas por trabalho de parto pré-termo com bolsa integra (TPP) e ruptura prematura pré-termo de membranas (RPPM) entre a $24^{\mathrm{a}}$ e a $34^{\mathrm{a}}$ semana de gravidez. Os desfechos secundários avaliados incluíram os efeitos perinatais da terapia antibiótica sobre a ocorrência de síndrome de desconforto respiratório (SDR), hemorragia intraventricular, enterocolite necrosante (ENC), sepse neonatal e óbito. Ademais estudamos a eficácia da terapêutica sobre o período de latência, ocorrência de corioamnionite clínica e morbidade febril puerperal.

Material e Método: O grupo de estudo foi constituído por 34 mulheres em trabalho de parto pré-termo com bolsa integra e 47 com ruptura prematura pré-termo de membranas que foram alocadas de forma aleatória para receber amoxicilina e metronidazol (41) ou placebo (40), durante 10 dias ou até o parto, se este ocorresse antes do décimo dia. Todas as pacientes foram submetidas à tocólise com terbutalina por via endovenosa e corticoterapia antenatal, além de avaliação sistemática do bem-estar fetal através da dopplerfluxometria das artérias umbilicais e cerebrais médias. A idade materna média foi de 22,6 anos e a idade gestacional média na inclusão, de 30,3 semanas, sendo a dilatação cervical inferior a $3 \mathrm{~cm}$ em $95 \%$ dos casos.

Resultados: O intervalo médio entre a inclusão e o parto nos casos que utilizaram antibióticos foi de 13 dias em contraste com 8 dias no grupo controle, diferença sem significância estatística. Nas pacientes que apresentaram TPP este intervalo atingiu 15,6 dias no grupo tratado e 10,0 dias no grupo controle; os casos de RPPM alocados para terapia antibiótica tiveram um prolongamento da gravidez de 10,5 dias verso 6,6 dias para o grupo que utilizou placebo. Evidenciamos redução significativa em todos os parâmetros de morbidade neonatal estudados (SDR 21.9\% x 40\%, hemorragia intraventricular $4,8 \%$ × $20 \%$, sepse $7,3 \%$ x $20 \%$ ). Não observamos nenhum caso de enterocolite necrosante entre os 81 recém-nascidos avaliados. Ocorreram 3 óbitos neonatais sendo um no grupo tratado e dois no grupo controle. Entre as 47 pacientes com RPPM verificamos período de latência médio de 10 dias no grupo que utilizou antibiótico e de 7 dias para o grupo placebo (não significante). Foram diagnosticados 5 casos de corioamnionite clínica sendo um no grupo tratado $(2,4 \%)$ e quatro no grupo controles (10\%). A ocorrência de morbidade febril puerperal também foi superior no grupo controle $(17,5 \% \times 7,3 \%)$.

Conclusão: A ministração profilática de antibióticos para pacientes de risco para parto pré-termo apresentou efeitos benéficos maternos e neonatais, especialmente em gestações complicadas por ruptura prematura pré-termo de membranas.

Palavras-chave: Prematuridade. Antibioticoterapia. Mortalidade perinatal. Ruptura prematura de membranas. 


\section{Estudo da Secreção do Paratormôrnio (PTH) em Mulheres Normo e Hipoestrogênicas Submetidas a Hipocalcemia Induzida por Infusão Endovenosa de EDTA}

Autora: Letícia Cebrian Reis Pereira

Orientador: Prof. Dr. Marcos Felipe Silva de Sá

Dissertação de Mestrado apresentada ao Departamento de Ginecologia e Obstetrícia na Faculdade de Medicina de Ribeirão Preto da Universidade de São Paulo, em 6 de agosto de 2001.

A osteoporose é uma doença prevalente no período do climatério e que gera grande impacto social, econômico e pessoal Vários pontos de sua fisiopatologia já foram esclarecidos e sabe-se que sofre influência de vários fatores, dentre eles: fatores genéticos, baixo pico de massa óssea, baixo peso corporal, tabagismo alcoolismo, sedentarismo, sexo feminino, patologias crônicas, hipotestrogenismo e distúrbios do paratormônio (PTH) e vitamina D. Porém, ainda permanece obscura a relação entre dois hormônios importantes para $o$ metabolismo ósseo, o estradiol e o PTH, sendo de fundamental importância o esclarecimento dessa interação para uma melhor compreensão da fisiopatologia, profilaxia e tratamento da osteoporose.

Objetivo: O objetivo desse trabalho foi analisar a secreção de PTH em mulheres no menacme e na pósmenopausa (normo e hipestrogênicas), após hipocalcemia induzida por infusão endovenosa de EDTA.

Pacientes e métodos: Foram estudadas 14 pacientes: 7 mulheres no grupo controle, com idade entre 25 e 35 anos, no menacme, normoestrogênicas, com ciclos regulares, sem uso de contraceptivo hormonal e com FSH $<15 \mathrm{mil} / \mathrm{ml}$; 7 mulheres com mais de 5 anos de menopausa natural, sem terapia de reposição hormonal há mais de 6 meses e FSH>30 mil/ml. Foram excluídas as pacientes que apresentavam fatores que interferem na massa óssea, tais como: tabagismo, alcoolismo, doenças crônicas, IMC $<17 \mathrm{~kg} / \mathrm{m}^{2}$, cálcio iônico basal alterado ou uso de medicamentos como corticóides, antimetabólicos, antiepiléticos, anticoagulantes e suplementação vitamínica ou de cálcio. Essas 14 pacientes foram submetidas a um teste de estímulo da secreção de PTH, que consiste em um período de repouso de 30 minutos e posterior indução de hipocalcemia induzida por infusão endovenosa contínua de EDTA (30 mg/kg), durante 2 horas, com bomba de infusão contínua. Durante o repouso foram colhidas amostras de sangue venoso para determinações basais de FSH, estradiol, osteocalcina, cálcio iônico e PTH e durante os 120 minutos do teste foram coletadas amostras de sangue venoso de 10 em 10 minutos para dosagens de cálcio iônico e PTH. As pacientes colhiam também a segunda urina do dia para dosagens de deoxipridinolina e creatinina urinária e foram submetidas à densitometria óssea.

Resultados: A idade média das pacientes do grupo con- trole (C) foi de 30,86 anos e do grupo na pós-menopausa (M) foi de 64,71 anos, com média de 19,57 anos de menopausa. As pacientes do grupo $\mathrm{C}$ e $\mathrm{M}$ tiveram respectivamente peso médio de $67,8 \mathrm{~kg}$ e $52,26 \mathrm{~kg}$ e IMC médio de $25,97 \mathrm{~kg} / \mathrm{m}^{2}$ e $23,06 \mathrm{~kg} / \mathrm{m}^{2}$, sem diferença estatística entre eles. O FSH médio nos grupos $\mathrm{C}$ e $\mathrm{M}$ foi de $2,97 \mathrm{mUI} / \mathrm{ml}$ e $74,14 \mathrm{Mil} / \mathrm{ml}$, e o estradiol médio foi de $105,5 \mathrm{pg} / \mathrm{ml}$ e $22,0 \mathrm{pg} / \mathrm{ml}$, respectivamente. A média dos valores sangüineos basais de cálcio iônico nos grupos C e M foi de 1,17 mmol/1 e 1,24 mmol/1, sem diferença estatística. Foram calculadas as áreas sob as curvas de cálcio iônico durante todo o teste e após o início da infusão de EDTA e não foram encontradas diferenças estatísticas entre os grupos C e M. A média dos valores séricos basais de PTH nos grupos $\mathrm{C}$ e $\mathrm{M}$ foi de $27,08 \mathrm{pg} / \mathrm{ml}$ e $33,73 \mathrm{pg} / \mathrm{ml}$, sem diferença estatística. Foram calculadas as áreas sob as curvas de PTH durante todo o teste e após o início da infusão de EDTA e não foram encontradas diferenças estatísticas entre os grupos C e M. Num segundo momento as pacientes na pós-menopausa foram subdivididas em dois subgrupos: com e sem osteoporose, e as mesmas análises anteriores foram aplicadas nesses dois grupos. Os subgrupos com e sem osteoporose apresentaram respectivamente: média de idade de 65,25 anos e 64 anos, média de 22,25 anos de menopausa e 16 anos de menopausa e IMC médio de $21,95 \mathrm{~kg} / \mathrm{m}^{2}$ e $24,53 \mathrm{~kg} /$ $\mathrm{m}^{2}$. A média dos valores sangüíneos basais de cálcio iônico foi de 1,225 mmol/1 e 1,257 mmol/1 e as áreas sob as curvas de cálcio iônico também não apresentaram diferença estatística. Quando analisamos os dados sobre PTH nos subgrupos com e sem osteoporose, encontramos respectivamente: média dos valores séricos do PTH basal e $19,68 \mathrm{pg} / \mathrm{ml}$ e $52,47 \mathrm{pg} / \mathrm{ml}$ e ASC total de PTH de 15520 e 25290 , ambos com diferença estatística entre os dois subgrupos $(p=0,03)$. Conclusão: No presente estudo não foi observada relação direta entre os níveis de estrogênios (normo e hipoestrogênismo) e alteração na secreção de PTH foram significativamente mais elevados do que naquelas com osteoporose, o que corrobora a existência de um efeito anabólico do PTH sobre o tecido ósseo, em situação fisiológica.

Palavras-chave: Hipocalcemia. Paratormônio. Climatério. Osteoporose. 